\title{
O Uso do Plano de Tutoria na Prática Docente do Tutor Online na Universidade Aberta do Brasil
}

\section{The Use of the Tutoring Plan in the Online Tutor's Teaching Practice at the Open University in Brazil}

\section{Emmanuele Maria Correia Costa*}

\section{Cleide Jane de Sá Araújo Costa}

Universidade Federal de Alagoas - Ufal.

Av. Lourival Melo Mota, Tabuleiro dos

Martins -Maceió, AL - Brasil.

* emmanuele.correia@gmail.com

\section{Resumo}

O estudo investiga contribuições do plano de tutoria para a prática do tutor na UAB/EaD de um curso da Universidade Federal de Alagoas, com objetivo de analisar a efetividade dos planos de tutoria na ação do tutor e se eles são instrumentos de suporte que auxiliam no processo de aprendizagem dos estudantes da EaD. É um estudo de caso de natureza qualitativa com finalidade de perceber a prática do tutor a partir do uso dos planos de tutoria que auxiliam no processo de aprendizagem dos estudantes. Para a coleta de dados, realizou-se pesquisa bibliográfica com base no Guia do Tutor da Coordenadoria Institucional de Educação a Distância da Ufal, análise dos planos de tutoria e aplicação de questionário com tutores. O problema referiu-se às contribuições do plano de tutoria para a prática pedagógica do tutor no processo de aprendizagem na sala de aula virtual. Os resultados apontam que os planos de tutoria são efetivos na ação docente do tutor e são instrumentos de suporte que contribuem para o processo de ensino e aprendizagem desde que respeitem os elementos mínimos considerados essenciais pela Coordenadoria Institucional de Educação a Distância (CIED), estejam descritos de forma clara e objetiva e ser socializados entre os tutores, com vistas a favorecer uma efetiva ação docente.

Palavras-chave: Plano de tutoria, Tutoria, Planejamento, Aprendizagem. 


\section{The Use of the Tutoring Plan in the Online Tutor's Teaching Practice at the Open University in Brazil}

\section{Abstract}

The study investigates contributions of the tutoring plan in the tutor practice at the OUB/DE of a course at the Federal University of Alagoas with the objective of analyzing the effectiveness of the tutoring plans in the tutor's action and whether they are support tools that help in the learning process of the students of the DE. It is a case study of a qualitative nature with the purpose of perceiving the practice of the tutor from the use of the mentoring plans that aid in the learning process of the students. For data collection, a bibliographic research was carried out based on the Tutor's Guide to the Institutional Coordination of Distance Education of UFAL, the analysis of the tutoring plans and the application of a questionnaire with tutors. The problem was: What are the contributions of the tutoring plan to the pedagogical practice of the tutor in the learning process in the virtual classroom? The results show that tutoring plans are effective in the tutor's teaching action and are support tools that contribute to the teaching and learning process, as long as they respect the minimum elements considered essential by the Institutional Coordination of Distance Education (ICDE) and are described in a clear and objective way, to be shared among the tutors, in order to favor an effective teaching action.

Keywords: Tutoring plan, Mentoring, Planning, Learning.

\section{Introdução}

A EaD é definida pelo MEC (Brasil, 2005) como uma modalidade de ensino na qual a mediação didático-pedagógica no processo de ensino e aprendizagem é apoiada pelas tecnologias de informação e comunicação (TIC), com alunos e professores a desenvolver atividades educativas em diferentes lugares e em tempos diversos.

Na perspectiva da EaD, o tutor possui papel fundamental ao atuar junto com coordenador, monitor, alunos e professores no desenvolvimento e acompanhamento de atividades durante um período letivo. A tutoria é um trabalho docente que exige compreensão e envolvimento dos conteúdos, das temáticas durante os módulos das áreas. O tutor é o vínculo de ligação entre professores e alunos na prática pedagógica. Esse profissional apoia os professores, debate, aprofunda temas, contribui com as turmas, organiza o processo de acompanhamento e avaliação desses alunos por meio da mediação e interatividade no Ambiente Virtual de Aprendizagem (AVA) (Domeniqueli, 2008).

Com o intuito de orientar o tutor e todos os envolvidos nos cursos de EaD da Universidade Federal de Alagoas (Ufal) e da Coordenadoria Institucional de Educação a Distância (Cied) em parceria com o Núcleo de Tutoria, elaborou-se o Guia do Tutor como material de suporte para o desenvolvimento das atividades de tutoria da instituição. Nesse guia é possível encontrar informações relevantes sobre EaD e a tutoria da Ufal, bem como a concepção de tutor, suas atribuições, a sistemática de atividade, a legislação e o plano de tutoria - que será o foco deste estudo. Para o pleno exercício das suas ações, o tutor precisa ter conhecimento dos conteúdos do curso e da disciplina que irá ministrar, além de formação compatível. Cabe ao professor disponibilizar com antecedência ao tutor o plano de ensino, o material didático e o plano de tutoria. Nesse contexto, este estudo visa compreender visão dos tutores online vinculados a 
um curso de graduação na modalidade EaD/UAB sobre as contribuições dos planos de tutoria como instrumento de suporte ao tutor para auxiliar no processo de ensino-aprendizagem dos alunos.

\section{Modelo de Mediação Pedagógica e Docência na EaD/UAB}

A docência na EaD acontece sob múltiplas perspectivas, que envolvem as formas de ensinar e aprender. Há preocupação em desenvolver propostas para que o aprendizado aconteça de forma significativa. Para que isso ocorra, o docente na EaD precisa compreender-se como mediador da aprendizagem. É nessa perspectiva que a mediação pedagógica entra em evidência.

De acordo com Ferreira (2013), a mediação deve se fazer presente em todo o processo, visando oferecer ao estudante condições e meios necessários para apropriação do conhecimento. Nessa ótica, o professor na EaD assume diversas funções e se integra a uma equipe multidisciplinar.

Segundo Mill (2014), para que a EaD mediada pelas TIC seja implementada, é necessário um conjunto de profissionais que, atuando de forma coletiva, distribuída e colaborativa, desempenham o papel típico do professor da educação tradicional. Desse modo, tarefas como conhecer os alunos, planejar a aula e os conteúdos que serão trabalhados, escolher os recursos didáticos, elaborar atividades e avaliações, aplicá-las, corrigi-las e acompanhar o processo de ensino-aprendizagem de cada aluno e manejo da turma são distribuídas a vários profissionais que, em conjunto, formam o que ele denominou "polidocência".

Além disso, para atuar na EaD o professor precisa de conhecimentos pedagógicos, de conteúdo, de compreender e utilizar as TIC em sua mediação pedagógica; ter capacidade para lidar com informações; saber gerenciar o tempo; e possuir capacidade para trabalhar em equipe.

Nesse sentido, a mediação pedagógica é imprescindível para que a aprendizagem ocorra. Por mediação pedagógica Masetto (2008) define a atitude do professor que se coloca como facilitador, incentivador ou motivador da aprendizagem, que se apresenta com disposição de ser uma ponte entre o aprendiz e sua aprendizagem. Ele complementa que a medicação pedagógica coloca em evidência o papel do aprendiz como sujeito, fortalecendo-o como ator, o que lhe permitirá aprender e conseguir atingir seus objetivos.

\section{O Tutor no Modelo UAB, Atribuições e Funções}

O tutor faz parte do sistema EaD, analisar suas concepções e práticas é fundamental. Para Bezerra e Carvalho (2008), o tutor é oprofissional que atua diretamente com os alunos. Cabe ao tutor orientar, esclarecer dúvidas e acompanhar o estudo do aluno, ou seja, é um professor que deve mediar todo o processo de ensino e aprendizagem.

Gonzalez (2013) defende que o trabalho da tutoria guarda em si a essência da ação educativa desenvolvida pelo professor. O tutor é um educador como qualquer outro envolvido no programa, sendo essencial estabelecer mediações entre o estudante e as informações. Ele fornece as direções a lidar com o ritmo diferenciado de cada aluno, a dispor o conhecimento tecnológico e o material disponibilizado no curso, a ser ativo em seu trabalho, ter organização e liderança em seu grupo, ou seja, possibilitar a construção do conhecimento.

Desse modo, de acordo com Costa, Paraguaçu e Pinto (2009), a interação com a tutoria é uma forma de propiciar ao estudante da EaD uma relação que apenas outro sujeito pode fornecer, contribuindo com sua formação, com suas experiências, com sua subjetividade. São essas ações educativas que contribuem para desenvolver e potencializar as capacidades básicas dos estudantes, orientando-os no processo interativo a obter crescimento intelectual e autonomia. 
Sathler (2008) enfatiza que a tutoria possui papel fundamental no acompanhamento dos alunos, pois é um elo entre os discentes com os docentes e a equipe técnica.

Na visão de Spressola (2008), o tutor deve ter uma série de qualidades que garanta a eficiência do acompanhamento, do atendimento e das informações prestadas aos alunos, como: proatividade, cultura social, empatia, estabilidade emocional, cordialidade, liderança e capacidade de audição e de aceitação, entre outras.

De acordo com Silva e Figueiredo (2011), o tutor transmite as atividades propostas pelos professores aos alunos, ensina os discentes a utilizar as tecnologias, distribui o material didático; cumpre a função de motivar, gerenciar os encontros presenciais e identificar as dificuldades acadêmicas e administrativas.

Berti e Vermaas (2012) complementam que o tutor necessita buscar artifícios para diminuir a distância no relacionamento com seus alunos. É preciso criar um ambiente agradável de reflexão e interação entre os participantes que favoreça a aprendizagem. A interatividade e a afetividade nos relacionamentos entre esses participantes devem ser consideradas pontos-chave, pois, motivados, os alunos tendem a possuir maior facilidade de aprendizagem.

Mill (2014) afirma ainda que o tutor é elemento central do processo educacional; portanto, a qualidade do seu trabalho é primordial para a aprendizagem dos estudantes.

De acordo com a Resolução CD/FNDE n. 8, de 30 de abril de 2010, tutor é o profissional selecionado pelas instituições públicas de ensino superior (IPES) vinculadas ao Sistema UAB para o exercício das atividades típicas de tutoria, sendo exigida formação de nível superior e experiência mínima de um ano no magistério do ensino básico ou superior, ter formação pós-graduada ou estar vinculado a um programa de pós-graduação. O tutor destaca-se como mediador no processo de ensino-aprendizagem, sendo o responsável pela motivação dos alunos e pela criação de oportunidades de aprendizagem. Ele acompanha os alunos durante o desenvolvimento das atividades de cada disciplina, orientando-os na sua realização. É o responsável pela avaliação da aprendizagem, fornecendo nota ao final de cada módulo. É um profissional que domina o conteúdo da disciplina de forma a auxiliar os alunos a sanar suas dúvidas.

No que tange ao padrão da UAB, o tutor é um bolsista com formação na área do conhecimento do curso ou disciplina que vai atuar. É ele que acompanha o processo de ensino-aprendizagem. Seu trabalho é desenvolvido em parceria com o professor, envolvendo-se nas atividades de docência, pois atua nas atividades do aluno ao interagir com eles e orientá-los.

Nesse sentido, demonstra a necessidade da existência de um plano de tutoria como forma de estabelecer estratégias de acompanhamento sistemático do processo de aprendizagem dos alunos. Cabe ao professor disponibilizar com antecedência para o tutor o plano de ensino, o material didático e o plano de tutoria.

\section{O Plano de Tutoria como Instrumento da Ação Tutorial}

Moore e Kearsley (2007) frisam que os cursos em EaD baseiam-se num guia de estudo; este oferece um roteiro do curso e a estrutura que serve de apoio a outros materiais. Esses guias ou manuais em EaD configuram-se como parte integrante do material didático. O manual é um material que pode ser dirigido ao professor como recurso de orientação do ensino ou ao aluno, apresentando de forma clara e objetiva o conteúdo a ser estudado, de modo a oferecer informações suficientes à sua compreensão. O guia de estudo ou manual é um recurso suplementar e de orientação sobre como participar de um curso em EaD (Fernandez, 2009). 
Os guias de estudo ou manuais apresentam a organização e a estrutura do curso, sendo direcionados para o aluno e para o professor tutor. Os profissionais que criam os cursos dedicam muita atenção aos guias, pois eles constituem um apoio para as demais tecnologias, contêm instruções e orientações sobre a estrutura da disciplina e a forma de interação, bem como sobre as metas e os objetivos a respeito da disciplina (Moore; Kearsley, 2007).

Ao propor que um curso seja oferecido na EaD, é preciso pensar em como ele será: sua estrutura, recursos humanos, preparação e distribuição do material didático, organização do plano de ensino e das aulas, organização administrativa e de responsabilidades. A estrutura envolve todos os recursos materiais e de espaço necessários e adequados para apoiar a proposta do curso.

Por meio do item recursos humanos delineia-se quem serão os participantes, suas funções no curso e responsabilidades. Isso envolve coordenadores do curso, pessoal para atendimento aos alunos, equipe técnica e administrativa, professores e tutores. A preparação e distribuição do material didático e a construção dos planos de ensino e de aula são de extrema importância e devem estar de acordo com os princípios pedagógicos e técnicos do curso. Além disso, devem ser pensados em conjunto com a estrutura e perfil dos recursos humanos que farão parte dessa arquitetura pedagógica.

A equipe de profissionais envolvidas nesse processo precisa ter clareza dos princípios pedagógicos, dos objetivos do curso, do perfil dos atores envolvidos e de suas especificidades, assim como conhecer a proposta e suas implicações. Todos os aspectos mencionados estão interligados e devem estar de acordo para que o curso possua coesão e qualidade. Com base nessa concepção, o professor e o tutor auxiliam e criam deliberadamente meios para ajudar o aluno a aprender; o aluno precisa se propor deliberadamente a aprender (Konrath et al., 2009). Além disso, deve haver ação dialógica entre professor e tutor para que o bom desempenho do processo de ensino-aprendizagem ocorra na EaD.

De acordo com o Guia do Tutor (Ufal, 2014), o plano de tutoria é um instrumento que orienta as atividades de tutoria; logo, sua proposição pelo professor é indispensável. O plano de tutoria resulta do planejamento da disciplina e pode ser entendido como o produto final do planejamento, que se materializa no registro escrito, sistematizado e com justificativa sobre: o que será feito? Para quem será feito? Por que será feito? Como será feito? Quando será feito?

Para o desenvolvimento da disciplina ou unidade curricular, o professor tem como parâmetro para suas ações o plano da disciplina ou plano de ensino, instrumento constituído pelos principais elementos do planejamento: identificação da disciplina ou unidade curricular; ementa; objetivo geral e objetivos específicos; conteúdos; metodologia; avaliação; cronograma e referências.

O plano de disciplina ou plano de ensino apresenta a concepção pedagógica que orientou a produção e a seção do material didático e deve conduzir a elaboração do plano de aula. O plano de aula é a previsão dos conteúdos e atividades de uma ou das várias aulas que compõem uma unidade de estudo. Nele, o professor prevê o detalhamento das ações, como: apresentação das atividades, materiais e recursos a serem utilizados. Alguns elementos para a construção do plano de aula são essenciais: objetivos específicos, conteúdo, estratégias de ensino, recursos, forma de avaliação de aprendizagem e cronograma. Esses instrumentos - plano da disciplina ou de ensino e plano de aula - servirão de base para que o professor construa o plano de tutoria na EaD (Guarezi; Grudtner, 2007).

Guarezi e Grudtner (2007) ressaltam a necessidade de professores e tutores discutirem o plano de trabalho e o material a ser trabalhado em parceria antes do início do curso. Esse deve ser um momento

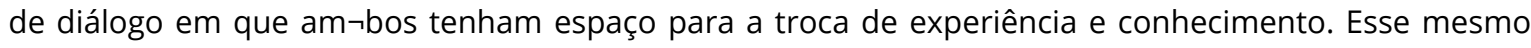
espaço deve ser mantido periodicamente, pois ao longo disciplina, unidade curricular ou módulo certamente será necessária a revisão e/ou ajuste dos conteúdos, materiais, recursos e atividades, entre outros. Segundo as autoras, planejamento é o ato de refletir sobre as possibilidades de escolhas e, consequen- 
temente, de ações a serem tomadas; envolve uma ação dialética, com possibilidade de diálogo constante entre reflexão e ação.

Ainda de acordo com Guarezi e Grudtner (2007), na EaD o plano de tutoria é uma ferramenta indispensável à prática do tutor. Por meio desse plano, os tutores podem se orientar para o apoio mais interativo e efetivo dos alunos. Desse modo, pode-se defini-lo como um instrumento que orienta as atividades dos tutores e norteia as ações do tutor, pontuando suas atividades e estabelecendo os procedimentos para o acompanhamento do processo de ensino e aprendizagem dos alunos em EaD.

O Guia do Tutor da Ufal (2014) é um documento que se encontra disponível no site da Cied (http:// www.ufal.edu.br/cied). Nele, o plano de tutoria configura-se como uma parte integrante do material didático na EaD. Com base nele, o tutor poderá desenvolver seu trabalho de forma clara e concisa, em conformidade com o que estiver estabelecido, no que se refere aos objetivos do curso ou disciplina, bem como os critérios a serem solicitados pelo professor.

A incorporação do plano de tutoria ao processo formativo deve incluir, de forma explícita e formalizada, uma série de elementos e procedimentos de uso das ferramentas incorporadas. Tais elementos e procedimentos de uso são essenciais e constituem um referencial inicial com base no qual o tutor norteará a organização das atividades em torno dos conteúdos e das tarefas de ensino e aprendizagem, ou seja, as estruturas de participação ou os sistemas de regras que estabelecem quem pode dizer ou fazer o que durante a realização das atividades de ensino e aprendizagem previstas na disciplina. O plano de tutoria proposto no Guia do Tutor da Ufal (2014) foi construído com base no guia do tutor da UAB, nas diretrizes para a qualidade do desempenho da tutoria a distância e na proposta de Guarezi e Grudtner (2007). Os elementos que compõem o plano de tutoria encontram-se no Quadro 1.

Quadro 1: Modelo de planos de tutoria Ufal (2014) x Guarezi e Grudtner (2007).

\begin{tabular}{|c|c|}
\hline $\begin{array}{c}\text { Plano de Tutoria } \\
\text { (Ufal, 2014) }\end{array}$ & $\begin{array}{c}\text { Plano de Tutoria } \\
\text { (Guarezi e Grudtner, 2007) }\end{array}$ \\
\hline Identificação da disciplina & Objetivos \\
Perfil da turma & Conteúdo \\
Objetivos & Estratégias de ensino \\
Estratégias de ensino & Recursos didáticos \\
Conteúdo & Avaliação \\
Avaliação & Cronograma \\
Cronograma & \\
Atribuições do tutor & \\
\hline
\end{tabular}

É importante frisar que os objetivos descrevem o conjunto de conhecimentos, habilidades, atitudes e competências que será mobilizado pelos alunos no processo de aprendizagem. As estratégias de ensino são métodos, técnicas e processos a serem utilizados pelo professor e pelo tutor para mediar o processo de ensino e aprendizagem. Contêm os procedimentos para o tutor conduzir o acompanhamento. $\mathrm{O}$ professor descreve como a atividade deve ser conduzida e as intervenções para que o acompanhamento do tutor possa atender aos objetivos da atividade. Os conteúdos são os conhecimentos sistematizados e organizados que serão utilizados pelo professor, pelo tutor e pelos alunos. Os recursos didáticos referemse às ferramentas e aos recursos para ampliar as possibilidades de aprendizagem. A avaliação, por sua vez, é o processo pelo qual se pode verificar se ocorreu a aprendizagem. Deve pontuar os aspectos que serão observados no acompanhamento dos alunos.

O plano de tutoria tem significativa importância, pois com base nele o tutor poderá desenvolver seu trabalho de forma clara e concisa, de acordo com o que estiver estabelecido no plano e tendo como referência os objetivos do curso ou da disciplina, bem como os critérios de avaliação e correção das atividades a serem solicitadas pelo professor. Para que o tutor possa exercer sua função de mediador da aprendiza- 
gem, necessita de informação, apoio, recursos, oportunidades de desenvolvimento e competências. Além disso, antes de iniciar os trabalhos o tutor necessita conhecer a filosofia específica da EaD e da instituição de ensino; ter uma definição clara da sua função; os objetivos; o material didático a ser utilizado (Ufal, 2014).

De acordo com Ramos (2014), o tutor participa da avaliação do desempenho do aluno e do fornecimento do feedback, o que contribui para a aprendizagem na EaD. Para isso, o tutor deve ter: informação sobre as expectativas dos alunos no que diz respeito à avaliação; conhecimento do regulamento e requisitos referentes à avaliação na instituição; acesso a uma segunda opinião; acesso ao autor do curso ou ao pessoal acadêmico para debater algum problema relativo ao material do curso; conhecimento dos recursos disponíveis na organização para responder a necessidades específicas dos alunos.

Polak (2009) afirma que o tutor necessita de parâmetros avaliativos a serem compartilhados com o professor que coordena a disciplina para que possa auxiliar o processo de ensino e aprendizagem. Uma vez que o tutor, ao avaliar o aluno, atribui a ele uma nota, devem existir critérios para que tanto o tutor como o aluno saibam o que está sendo avaliado e como está sendo avaliado. O estabelecimento de critérios avaliativos minimiza o poder avaliador, desmistifica a avaliação e torna o processo mais conveniente. Quando o aluno conhece como será avaliado e por quem ele está sendo avaliado, torna-se mais seguro e isso dá à instituição mais credibilidade.

Para que isso aconteça o plano precisa conter todas as informações necessárias ao bom andamento da disciplina, com vistas a melhorar a qualidade do trabalho do tutor. É um instrumento que norteia as atividades da tutoria e os procedimentos para o acompanhamento do processo de ensino e aprendizagem.

O importante é que antes do início das atividades o professor e o tutor disponibilizem um momento para socializar e discutir o plano de tutoria. Deve ser um momento de diálogo para a troca de experiências, a ser mantido periodicamente no decorrer da disciplina, pois será necessária a revisão dos conteúdos e matérias, a depender do andamento do processo.

O professor responsável pela disciplina elabora e ajusta o material didático, a fim de estabelecer o plano de tutoria; este envolve os processos de ensino e aprendizagem dos alunos e as atribuições do tutor para determinada disciplina. O plano de tutoria consiste numa tarefa docente que inclui a previsão de atividades didáticas e os objetivos, ou seja, é um meio de programar as ações docentes. É um instrumento que norteia todas as ações da disciplina; nele são expressos os objetivos que deverão ser alcançados e os conteúdos que serão aprendidos pelos alunos, bem como os instrumentos de ação pedagógica de ensino e aprendizagem para que o tutor possa acompanhar o processo de avaliação das atividades, que deve estar em harmonia com a proposta de avaliação do plano da disciplina.

De acordo com Lima (2013), a incorporação do plano de tutoria ao processo formativo deve incluir uma série de normas e procedimentos de uso, tais como: identificação da disciplina, identificação do professor, ementa do curso, objetivos da disciplina, metodologia de trabalho, avaliações e detalhamento da pontuação, tipo de atividade, prazos-limites para a entrega de atividades etc. Tais normas e procedimentos de uso são elementos essenciais e constituem um referencial inicial de como o processo de ensino e aprendizagem deve ser conduzido.

Com base no plano de tutoria, o tutor norteará a organização das atividades em torno dos conteúdos e das tarefas de ensino e de aprendizagem, respeitando os elementos mínimos do que foi proposto pelo professor, permitindo assim que tenha uma visão detalhada de sua atribuição na disciplina que acompanha.

Zuapa et al. (2014) desenvolveram um cheklist para o planejamento da atuação do tutor online que pode assemelhar-se ao plano de tutoria proposto pela Coordenadoria Institucional de Educação a Distância (Cied) da Ufal. Segundo a autora, "um professor deve elaborar propostas de atividades para a reflexão, 
oferecer suporte à resolução, sugerir fontes de informação alternativas, explicar e esclarecer dúvidas, bem como facilitar os processos de compreensão; guiar, orientar e apoiar".

O tutor traz assuntos gerais para serem estudados e analisados, estimula o pensamento crítico, questiona e avalia, além de responder adequadamente às mensagens dos alunos. $O$ tutor não pode atuar simplesmente como controlador de cronograma, "animador de excursão"; deve conhecer integralmente o conteúdo do curso, além de intervir quando necessário a fim de favorecer e ampliar o conhecimento de seus alunos. É fundamental que conheça a realidade e o contexto de seus alunos, fazendo um link entre alunos, curso e instituições de ensino superior (IES).

Zuapa et al. (2014) asseveram que o planejamento serve como suporte para agilizar e organizar a execução do trabalho do tutor online; o objetivo principal dessa etapa é preparar antecipadamente as bases necessárias para alcançar metas futuras, possibilitando um gerenciamento realista. Para isso, é necessário: elaborar um plano específico para cada turma que inicia; relacionar os objetivos de cada atividade com o conteúdo trabalhado; planejar atividades diferenciadas relacionadas aos conteúdos do curso; solicitar relação que contenha dados para contato de todos os alunos do curso; solicitar relação com dados para contato dos responsáveis administrativos da instituição, inclusive com suas respectivas atribuições; conhecer os recursos de biblioteca disponibilizados aos alunos da EaD; conhecer os serviços e recursos de apoio aos alunos com problemas de estudo, de ordem pessoal ou pessoas com deficiência; criar múltiplos espaços de trabalho, de interação e socialização; definir as regras vigentes para as aulas online; desenvolver formas de comunicação para evitar a solidão dos alunos; esclarecer suas expectativas sobre os papéis dos participantes; manter comunicação com os demais tutores envolvidos, respeitando ideias apresentadas por eles e por toda a equipe de EaD; esquematizar a atribuição de notas para cada trabalho/atividade; buscar regras para a entrega de trabalhos fora do prazo ou plágio.

\section{Metodologia}

Este estudo se configura na abordagem qualitativa, que, segundo Creswell (2010), tendo como metodologia um estudo de caso (Flick, 2009) considera-a mais adequada, na medida em que procura compreender, explorar ou descrever acontecimentos com vistas a observar a realidade da sociedade. Consistiu num estudo de determinados indivíduos, profissões, condições institucionais, grupos ou comunidades, com a finalidade de obter generalizações. $O$ trabalho com estudo de caso abrange momentos distintos: delimitação do caso, coleta de dados, seleção, análise, interpretação e elaboração do relatório do caso.

Trabalha com representações e opiniões subjetivas dos sujeitos envolvidos - neste caso, o tutor online -, com o intuito de investigar os planos de tutoria e a forma de intervenção utilizada pelos tutores de um curso de graduação da UAB/Ufal, no que se refere a um processo de ensino e aprendizagem com base na ação docente realizada pelo tutor dentro do AVA Moodle.

\section{Resultados e Discussão}

Os dados coletados e analisados foram extraídos das respostas ao questionário realizado com os tutores online e da análise dos planos de tutoria elaborados pelos professores. A partir disso realizou-se um questionário com vinte quatro tutores online vinculados à UAB/Ufal.

A pesquisa foi idealizada com uma população composta de 45 tutores; desse universo, apenas 24 (54\%) responderam às questões.

Primeiramente, aborda-se como ocorre a relação entre professor e tutor para socializar as ações do plano de tutoria, referente à disponibilidade do plano de tutoria antes do início da disciplina, os momentos 
de interação entre eles e de que forma a interação acontece. Nas respostas dos tutores referentes à disponibilidade do plano de tutoria antes do início da disciplina, 20 deles informaram que recebem o plano de tutoria, às vezes, antes do início da disciplina; dois afirmaram que nunca recebem o plano de tutoria; os outros dois asseveraram que sempre o recebem com antecedência. Para os tutores, quando o plano de tutoria é disponibilizado antes do início da disciplina, o tutor organiza antecipadamente suas atividades, o que otimiza o processo de tutoria.

Quanto aos momentos de interação entre professor e tutor, 17 respondentes informaram que às vezes existem momentos de interação; três tutores afirmaram que sempre ocorrem e quatro tutores informaram que nunca ocorrem.

Um dos pontos recorrentes na fala dos tutores é que, sem a interação com o professor, algumas atitudes poderão ficar prejudicadas e os tutores se sentirão limitados na condução da sua função. $O$ contato entre professor e tutor é necessário para que o tutor online possa interagir de forma a promover a aprendizagem do aluno - sua principal responsabilidade. $O$ tutor tem a função de acompanhar os alunos nesse processo, influenciando-os nessa caminhada por meio daquilo que realiza no caminho da produção cognoscente: ações intelectuais, interativas, motivacionais e comunicacionais (Pimentel, 2013).

A análise revela que o plano de tutoria é o material de apoio do tutor, mas não dispensa o diálogo e a interação entre professor e tutor, a fim de compreender a ação pedagógica a ser desempenhada.

As dificuldades encontradas para colocar em prática o plano de tutoria pelos tutores online se revelam a partir da fala dos tutores em suas respostas ao questionário, conforme mostra o Quadro 2.

Quadro 2: Elementos do plano de tutoria x dificuldades na interpretação.

\begin{tabular}{|l|c|}
\hline $\begin{array}{c}\text { Elementos do plano } \\
\text { de tutoria }\end{array}$ & $\begin{array}{c}\text { Respostas dos } \\
\text { tutores }\end{array}$ \\
\hline Objetivos & 7 \\
\hline Conteúdos & 5 \\
\hline Estratégias de ensino & 3 \\
\hline Recursos & 5 \\
\hline Avaliação & 12 \\
\hline Cronograma & 8 \\
\hline
\end{tabular}

O quadro mostra que os tutores apresentam dificuldades em identificar informações contidas no plano de tutoria, como objetivos, estratégias de ensino, conteúdos, recursos didáticos, avaliação e cronograma. Os tutores relataram que elas não estão claras no que se refere ao que o professor pretende que o tutor desempenhe junto aos alunos na realização das atividades no AVA.

Dos tutores, 22 responderam que o plano de tutoria é muito útil para a realização dos trabalhos e apenas dois tutores responderam que é pouco necessário. Nenhum tutor considerou o plano de tutoria desnecessário.

Com isso, confirma-se que o plano de tutoria faz parte da prática pedagógica na EaD, pois é nele que baseia todo o direcionamento do seu trabalho. É no plano de tutoria que constam os objetivos de cada atividade e como elas devem ocorrer.

A observação demostra também que o plano de tutoria esclarece dúvidas, aponta o caminho a trilhar e especifica o objetivo de cada atividade. É ele que vai respaldar o tutor para fornecer o feedback aos alunos 
e atribuir as notas às atividades realizadas pelos alunos. Sem ele, o tutor não tem parâmetros para a realização da mediação pedagógica de acordo com a proposta da disciplina. O plano de tutoria fornece ao tutor uma ação didática efetiva.

Os dados analisados revelam que os professores, ao elaborar o plano de tutoria, não sistematizam todos os elementos mínimos considerados essenciais na composição do plano; quando o fazem, apresentam algumas deficiências no que se refere à disposição das informações a serem direcionadas aos tutores, o que resulta na dificuldade de interpretação delas, prejudicando consequentemente a mediação pedagógica realizada pelos tutores online no AVA.

A relevância do plano de tutoria como elemento favorável à mediação pedagógica foi analisada a partir das respostas do questionário; 23 tutores responderam que o plano de tutoria é relevante para a melhoria do processo de ensino e aprendizagem; somente um tutor considera que o plano de tutoria não é relevante.

Do total, 21 tutores consideram que o uso efetivo do plano de tutoria possibilita a mediação pedagógica durante as interações no AVA como forma de potencializar a aprendizagem dos alunos; três tutores afirmaram que não há relação do uso do plano de tutoria com a mediação pedagógica.

A fala dos tutores demonstra que os planos de tutoria direcionam e organizam as ações pedagógicas do tutor no processo de mediação pedagógica. É por meio da mediação pedagógica que o estudante obtém as condições necessárias à assimilação do conhecimento. O plano de tutoria deve favorecer a mediação pedagógica, pois contém todos os dados necessários ao trabalho do tutor online.

Todos os tutores afirmam que, mesmo com experiência, o plano de tutoria é de suma importância para potencializar a prática docente, tendo em vista um melhor aproveitamento da aprendizagem dos alunos; por isso, o tutor não pode dispensar seu uso sem prejudicar a ação pedagógica.

Nesse item de análise, a fala dos tutores confirma que o uso do plano de tutoria é indispensável ao bom acompanhamento da disciplina, pois cada uma possui suas especificidades e objetivos de aprendizagem diferenciados.

Quanto aos critérios de correção constituintes do plano de tutoria, se atendem às expectativas dos tutores, oito tutores responderam que os planos de tutoria atendem a suas expectativas; 16 tutores disseram que às vezes; nenhum disse que nunca atendem. As expectativas dos tutores referem-se ao processo de mediação pedagógica que eles realizam junto aos alunos no AVA Moodle.

Foi possível constatar que a falta de detalhamento dos critérios de avaliação apresentados pelo professor da disciplina compromete o processo de avaliação dos alunos. Por isso, os critérios de avaliação poderiam ser discutidos em conjunto entre professor e tutor, com base no processo de interação; os tutores ressaltam que a falta de contato com o professor impede que as ações possam ser mais detalhadas.

Os planos de tutoria são efetivos quando se apresentam com uma estrutura mínima estabelecida pela Cied, desde que elaborados com identificação da disciplina; perfil da turma; objetivos; conteúdos; recursos didáticos; avaliação; cronograma; e atribuição do tutor.

$\mathrm{Na}$ análise dos planos de tutoria, revelou-se que, quando obedecem à estrutura mínima de elementos estabelecidos pela Cied e as informações são claras e precisas, eles são efetivos e se tornam instrumentos de suporte ao trabalho do tutor online, contribuindo para a aprendizagem dos alunos.

Quanto à pergunta inicial deste estudo, se o plano de tutoria auxilia de forma significativa na prática docente do tutor no processo de ensino e aprendizagem na sala de aula virtual, a resposta será sim desde que ele contemple alguns requisitos básicos de estrutura, objetividade, clareza e haja interação entre professor e tutor de forma antecipada e periódica para possíveis revisões e ajustes. 


\section{Considerações Finais}

No decorrer do percurso da EaD, muito se discute sobre a função da tutoria. Para que possa exercer sua função de mediador da aprendizagem, o tutor necessita de informação, apoio, recursos, oportunidades de desenvolvimento e competências.

Há necessidade de que professores e tutores discutam o plano de trabalho e o material a ser trabalhado em parceria antes do início do curso. Guarezi e Grudtner (2007) defendem o planejamento como ato de refletir sobre as possibilidades de escolha e, consequentemente, de ações a serem tomadas, o que envolve uma ação dialética com possibilidade de diálogo constante entre reflexão e ação. Para as autoras, o plano compreende o produto final do planejamento e se materializa com o registro escrito, sistematizado.

$\mathrm{Na}$ EaD, o plano de tutoria é uma ferramenta indispensável à prática do tutor. Por meio desse plano, os tutores podem se orientar para o apoio mais interativo e efetivo dos alunos. O plano de tutoria é um instrumento que orienta as atividades do tutor tendo como proposta nortear as ações dele, pontua suas atividades e guia os procedimentos para o acompanhamento do processo de aprendizagem dos alunos em EaD.

No tocante à análise da efetividade dos planos de tutoria na ação docente do tutor online e dos instrumentos de suporte que contribuem para o processo de ensino e aprendizagem, revelou-se a relevância do plano de tutoria, pois possibilita maior avanço no trabalho do tutor, no contínuo processo de mediação pedagógica que ele realiza.

Com isso, confirmou-se que o plano de tutoria faz parte da prática pedagógica na EaD, pois é nele que se baseia todo o direcionamento do trabalho que o tutor realiza. É no plano de tutoria que se observam os objetivos de cada atividade e como elas devem ocorrer. Ele fornece o direcionamento ao tutor, com vista ao melhor acompanhamento dos alunos.

A análise da prática docente do tutor online sugere uma promoção de melhorias na estruturação, bem como maior envolvimento com a equipe de produção do material didático e acompanhamento de um especialista em planejamento das ações em EaD.

Esse processo abre possibilidades para discussões posteriores sobre a dinâmica do trabalho de elaboração e a utilização do plano de tutoria, partindo do princípio de que o tutor precisa ter acesso a todo o material didático para o bom desempenho do seu trabalho.

\section{Referências Bibliográficas}

Berti, K. A. de F. \& Vermaas, L. L. G. L. (2012). Avaliação e gestão da tutoria: uma dupla dinâmica para o bom andamento do curso. In Simpósio Internacional de Ensino a Distância; Encontro de Pesquisadores em Educação a Distância. São Carlos. Disponível em: http://sistemas3.sead.ufscar.br/ojs1/index.php/sied/article/view/37/13.

Bezerra, M. de A. \& Carvalho, A. B. G. (2008). Tutoria: concepções e práticas na educação à distância. Disponível em: http://books.scielo.org/id/6pdyn/pdf/ sousa-9788578791247-10.pdf.

Brasil. Lei n 9.394, de 20 de dezembro de 1996 (1996). Estabelece as diretrizes e bases da educação nacional. Diário Oficial [da] República Federativa do Brasil, Brasília. Disponível em: http://www.planalto.gov.br/ ccivil03/leis/19394. htm.

Coordenação de Aperfeiçoamento de Pessoal de Nível Superior - Capes (2010). Universidade Aberta do Brasil: histórico. Disponível em: http://www.uab.capes.gov.br/index.php/sobre-a-uab/historico 
Costa, C. J., Paraguaçu, F. \& Pinto, A de C. (2009). Experiências interativas com ferramentas midiáticas na tutoria online. Em Aberto, 22(79), 121-137.

Creswel, J. W. (2010). Projeto de pesquisa: métodos qualitativos, quantitativos e misto. 3. ed. Porto Alegre: Artmed.

Domeniquelli, A. M. T. (2008). A organização do trabalho do professor-tutor. In L. Sathler \& A. B. Azevedo. Orientação didático-pedagógica em cursos a distância (pp. 36-46). São Bernardo do Campo: Umesp.

Fernandez, C. T. (2009). Os métodos de preparação de material impresso para EAD. In F. M. Litto; M. Formiga (Orgs.). Educação a distancia: o estado da arte. (pp. 395-402). São Paulo: Pearson Education do Brasil.

Ferreira, A. S. \& Figueiredo, M. A. (2015). Perfil do aluno da educação a distância no curso de didática do ensino superior (2011). Disponível em: https://www. ufmg.br/ead/seminario/anais/pdf/Eixo 2.pdf

Flick, U. (2009). Métodos de pesquisa: introdução à pesquisa qualitativa. 3. ed. Porto Alegre: Artmed.

González, L. A. S. (2013). Contextualizando o campo: a legis/ação e a Universidade Aberta do Brasil. In M. L. F. Carneiro; L. B. Turchielo (Orgs.). Educação a distância e tutoria: considerações pedagógicas e práticas (pp. 118-130). Porto Alegre: Evangraf.

Guarezi, R. \& Grudtner, S. (2007). Planejando as ações da tutoria. Disponível em: http://www.comunidade. sebrae.com.br/educacao/Documentos+para+download/Downloads_GetFile.aspx?id=15234

Konrath, M. L. P., Tarouco L. M. R. \& Behar P. A. (2009). Competências: desafios para alunos, tutores e professores da EAD. Revista Renote - Novas Tecnologias na Educação, 7(1), p. 1-10. Disponível em: http:// seer.ufrgs.br/renote/article/viewFile/13912/7819

Lima, M. A. de A. (2013). Planos de tutoria e expectativas do tutor da UAB. In Seminário Internacional de Educação a Distância. Belo Horizonte. Disponível em: http://www.abed.org. br/congresso2013/cd/326.doc

Masetto, M. T. (2008). Mediação pedagógica e o uso da tecnologia. In J. M. Moran, M. T. Masetto \& M. A. Behrens. Novas tecnologias e mediação pedagógica. São Paulo: Papirus.

Mill, D., Ribeiro, L. R. C. \& Oliveira, M. R. G. (2014). Polidocência na educação a distância: múltiplos enfoques. 2. ed. São Carlos: EdUFSCar.

Moore, M. G. \& Kearley, G. (2007). Educação a distância: uma visão integrada. São Paulo.

Morgado, E. \& Andrade, A. M. V. de. (2009). Avaliação da tutoria no ensino a distância. In IV Conference on Information Systems and Technologies, pp. 443-339. Póvoa de Varzim. Disponível em: http://www1.porto.ucp.pt/feg/docentes/aandrade/publicacoes/conferenciasavaliacao_tutoria_no_ensinoa_distancia.pdf

Pimentel, F. S. C. (2013). Interação online: o desafio da tutoria. EAD e educação online. Maceió.

Polak, Y. N. Avaliação do aprendiz em EAD (2009). In: F. M. Litto \& M. Formiga (Orgs.). Educação a distancia: o estado da arte. (pp. 153-160). São Paulo: Pearson Education do Brasil.

Ramos, M. da S. Qualidade da tutoria e a formação do tutor: os efeitos desses aspectos em cursos a distância (2013). In X Congresso Brasileiro de Ensino Superior, Belém. Disponível em: http://www.aedi.ufpa.br/ esud/trabalhos/poster/AT1/112988.pdf

Sathler, L. A tutoria em cursos superiores a distância (2008). In: L. Sathler \& A. Azevedo. Orientação didático -pedagógica em cursos a distância. (pp. 9-15). São Bernardo do Campo: Unesp.

Silva, C. G. \& Figueiredo, V. F. (2011). A importância do tutor para a aprendizagem no ensino a distância. Paidea@ Revista Científica de Educação a Distância, 2(4). Disponível em: http://revistapaideia.unimesvirtual.com.br/index.php?journal=paideia\&page=article\&op=view\&path[]=201\&path[]=176 
Spressola, N. A. (2008). Instrumento para avaliar as competências do trabalho do tutor na modalidade EaD. Dissertação de Mestrado. Universidade de São Paulo.

Universidade Federal de Alagoas. Coordenadoria Institucional de Educação a Distância. Guia do tutor. (2014). Disponível em: http://www.ufal.edu.br/cied/documentos/GUIADOTUTOR.pdf

Zuapa, A. P. et al. (2014). Planejamento para atuação dos tutores online. In XI Congresso de Ensino Superior a Distância. Santa Catarina. Disponível em: http://esud2014.nute.ufsc.br/anais-esud2014/files/ pdf/126881.pdf 